\title{
Ruptured true aneurysm of right superficial femoral artery
}

\begin{abstract}
Introduction: The frequency of isolated true aneurysm of superficial femoral artery (SFA) is about $1 \%$ of all femoral aneurysms. They affect elderly men predominantly. The prognosis of that pathology is favorable, but rupture may be presented in $35 \%$ of cases, modulating the therapeutic strategy and outcome of the disease.
\end{abstract}

Aim: To present a case report of patient with ruptured saccular aneurismal dilatation of right superficial femoral artery.

Materials and methods: We present a case report of 82years old man, with an anamnesis of Arterial hypertension, atrial fibrillation and heart failure, who was suffering of pain and swelling of his right hip some hours ago. A Computer angiography and Ultrasound Doppler sonography show a saccular aneurismal dilatation of right SFA with its rupture. The implemented resection and restitution of the mentioned blood vessel achieved an excellent post-operative result. In the present case report we used a documental data, and the laboratory, imaging and therapeutic methods were done in the relevant departments of "St. Anna" Hospital - Varna. We evaluate the available literature about that medical problem.

Conclusion: Presented case report is interesting as diagnostic and differential diagnostic problem, because of its rare frequency, which is similar to other vascular diseases. The appropriative diagnosis on time and adequate treatment is challenging and associated with satisfying results.

Keywords: aneurysm, rupture, femoral artery, atherosclerosis, blood vessels
Volume 6 Issue 6 - 2016

\author{
Ivelina Veselinova Borisova, Dobromirov P, \\ Cheshmedziev M \\ Department of Vascular surgery, Hospital “St. Anna”, Bulgaria
}

Correspondence: Department of Vascular Surgery "St.Anna" Hospital Bulgaria, 100 Tzar Osvoboditel Street,Varna, Bulgaria, Tel 3595282I552, Email ov4icata_I@abv.bg

Received: October 27, 2016 | Published: November 03, 2016

\section{Introduction}

True arterial aneurysm is a chronic disease, associated with abnormal dilatation of the blood vessels. On the base of their localization, peripheral and visceral aneurysms exist. The most common type is the first one. ${ }^{2}$ It is mentioned as a difficult problem in the vascular surgery, resulting of its different anatomical variants, hemodynamic disorders and complications. ${ }^{3}$

The most common peripheral aneurysm affects popliteal artery ( $70 \%$ of all cases), and on the second place $-23 \%$ femoral artery is involved. . 5,6 According to the Cutler and Darling's classification, femoral artery aneurysms are two types: type 1: aneurysm involves common femoral artery (CFA) only, not the bifurcation; type 2: aneurysmal disease of the bifurcation, the commencement of the profunda femoris artery (PFA), or superficial femoral artery (SFA). ${ }^{5}$

The isolated true arterial aneurysms of SFA, which not involves CFA or popliteal artery are so rare - only $1 \%$ of all femoral aneurysms. ${ }^{4,7}$ They affect elderly men predominantly. The prognosis is favorable, but rupture may occur in $35 \%$ of cases, modulating the therapeutic strategy and outcome of the disease. ${ }^{7}$

\section{Aim}

To present a case report of patient with ruptured saccular aneurismal dilatation of right SFA.

\section{Material and methods}

We present a case report of ruptured true aneurysm of right SFA in an elderly man. A brief review of the relevant literature was made. The patient was 82 years old, who was hospitalized on 24/05/16 in the Department of Vascular surgery, 'St. Anna” Hospital - Varna,
Bulgaria. His complains started last night as progressive swelling and pain in the right limb. On the next morning his condition became worse. There was a history of long-standing arterial hypertension, ischemic heart disease with coronary stent implantation, atrial fibrillation, chronic heart failure treated by common drugs, together with per oral anticoagulants. He was no smoker and did not drink alcohol. There was no history of previous traumas or surgery.

On the date of admission the patient had no fever and had elevated blood pressure $(160 / 80 \mathrm{mmHg})$. General evaluation was normal except cardiac auscultation, which revealed irregular heart beat with $88 \mathrm{bpm}$. The left lower limb femoral and popliteal pulses were normal, but the distal pulses on the same leg and the right popliteal and distal pulses were not presented. There was a large subfascial and painful swelling of the right thigh, suffusion in the inguinal part without sign of ischemic disorders of the shank and foot skin (Figure 1 and 2).

There were no significant blood test abnormalities, except elevated C-reactive protein. Electrolytes and renal function tests were normal. Performed color Doppler ultrasound of the lower leg vessels revealed an image with a greatest diameter of $38.32 \mathrm{~mm}$ within the topography of the SFA, poorly-defined limits and mural thrombus. These characteristics suggested a ruptured aneurysm of the SFA (Figure 3). Computed tomography angiography (CTA) revealed ruptured aneurysm of right SFA with a diameter of $34 \mathrm{~mm}$ (Figure 4 and 5).

The patient underwent exploratory surgery of the right lower limb. There was a large ruptured aneurysm $(40.5 \mathrm{~mm} / \mathrm{d}$ ) (Figure 6 and 7). The aneurysm was resected and the vascular segment was reconstructed without allo- or synthetic grafts implementation. Endto-end anastomosis was realized between proximal and distal part of the SFA. 


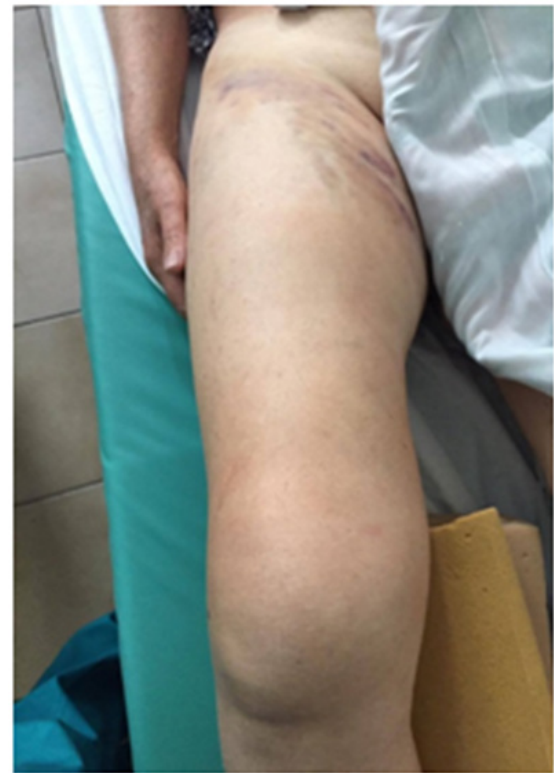

Figure I Swelling of the right limb.

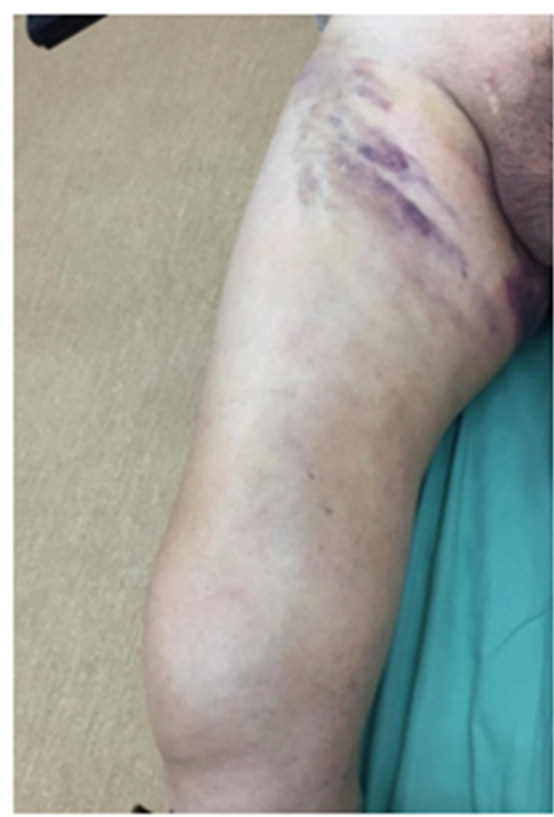

Figure 2 Skin suffusion of the right limb.

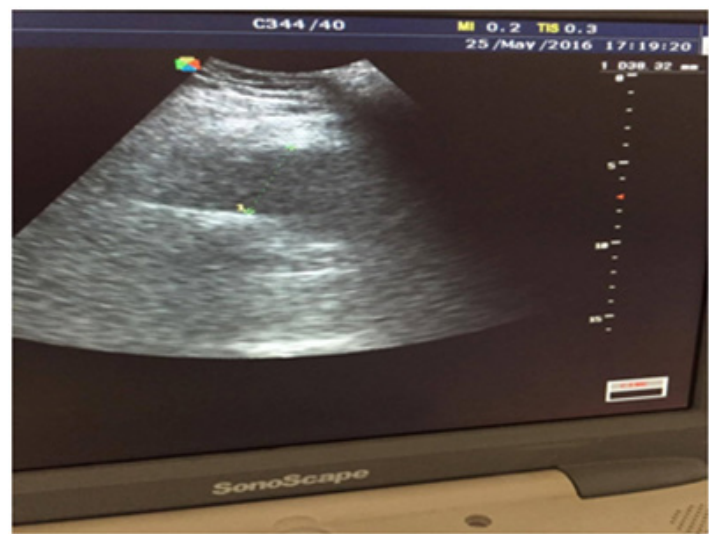

Figure 3 Ruptured aneurysm of the SFA.

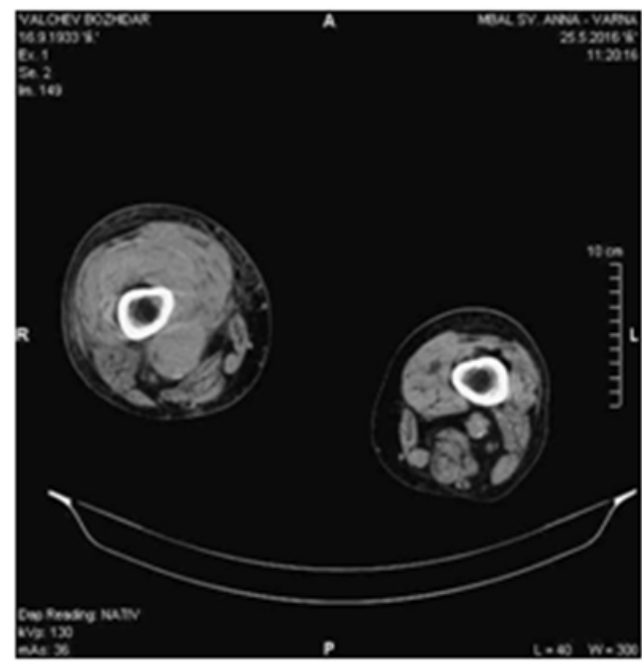

Figure 4 CTA image showing an aneurysm of the right SFA.

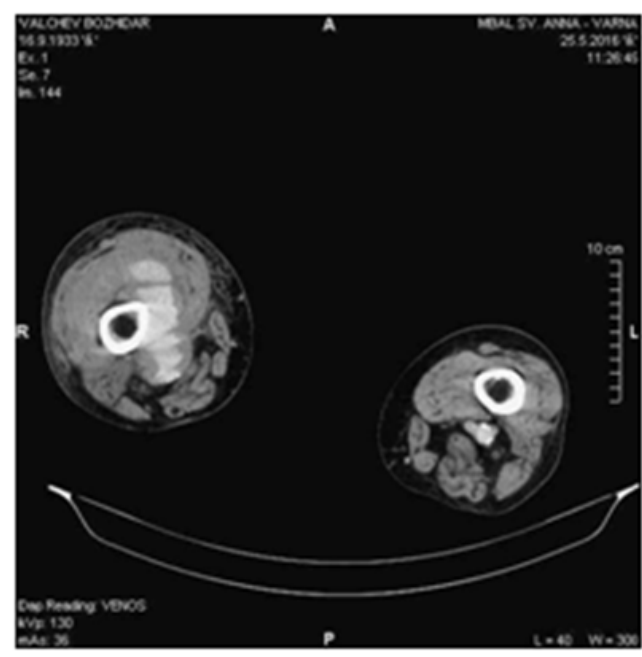

Figure 5 CTA image showing an ruptured aneurysm of the right SFA.

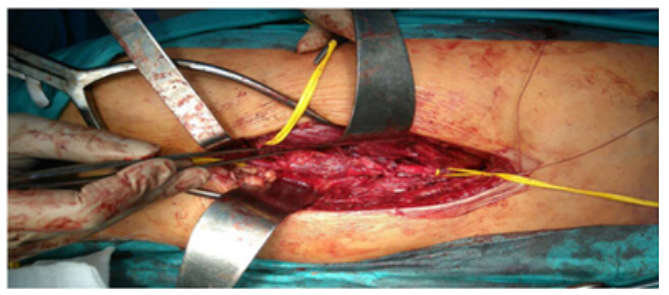

Figure 6 Surgical procedure, showing SFA aneurysm.

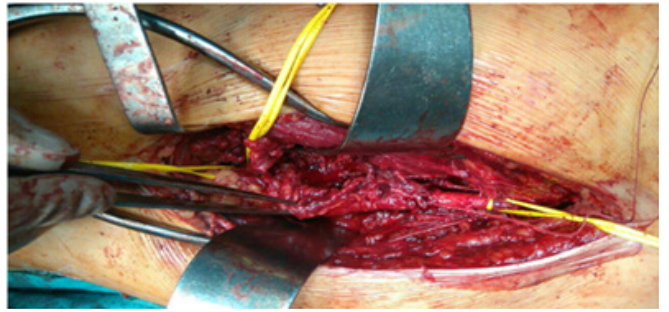

Figure 7 Surgical procedure, showing ruptured SFA aneurysm.

During the postoperative period, the patient was hemodynamically stable, afebrile. The operative wounds healed by primary intension. Manifestation of normal pulses of the popliteal artery in the right

Citation: Ivelina VB, Dobromirov P, Cheshmedziev M. Ruptured true aneurysm of right superficial femoral artery.J Cardiol Curr Res. 2016;6(6):I-6. DOI: I0.15406/jccr.2016.06.00232 
limb was a sign for the success working reconstruction. The patient was discharged from hospital 10days after the surgery. On the routine examinations there were no registered complications.

\section{Discussion}

The isolated true aneurysms of SFA are only $1 \%$ of peripheral true aneurysms. ${ }^{7}$ In the $75 \%$ of cases, they are associated with aneurysms of other localizations, and in $72 \%$ they are bilateral. ${ }^{1}$ Spontaneous rupture is a rare complication, occurring in $35 \%{ }^{7}$ The prognosis for the affected limb is poor, but the patient's life is not threated because of the massive fasciomuscular cover, which bound local bleeding. ${ }^{1}$ Surgical treatment of femoral aneurysm shows a capable results, and the (post) operative mortality is with low frequency. ${ }^{1,5}$ Vascular reconstruction without using synthetic grafts reduce the risk of infection. Presented case report is interesting as diagnostic and differential diagnostic problem, because of its rare frequency, which is similar to other vascular diseases. Sudden onset of swelling and severe pain of the lower limb, together with no registration of arterial pulsation distal from the affected area is suspicious for ruptured aneurysm of SFA. The diagnosis as soon as possible is challenging and adequate surgical treatment leads to satisfying results.

\section{Acknowledgements}

None.

\section{Conflicts of interest}

Author declares there are no conflicts of interest.

\section{Funding}

None.

\section{References}

1. Захариев Т, Аневризми на феморалните артерии в: Съдова хирургия, VI, София, 2008;73-74.

2. Стойчев Р, Андреев А, Истински Артериални аневризми в Съдови заболявания, София. 1998;109-14.

3. Тодоров К, Левичаров П, Съдова хирургия, София. 1990;125-29.

4. Arendt A, do Amaral R, Viera M. Ruptured true superficial femoral artery aneurysm. J Vasc Bras. 2013;12(4):315-319.

5. Davey Ph, Wyatt M. Aneurysmal Disease. In: Vascular Surgery, USA. 2006. p.191-214.

6. Jarrett F, Makaroun MS, Rhee RY, et al. Superficial femoral artery aneurysms: An unsusual entity? J Vasc Surg . 2002;36(3):571-574.

7. Rutherford RB. Superficial Femoral Artery Aneurysm. In: Rutherford RB, Vascular Surgery. WB Sauders, Philadelphia, USA. 2005. p. $1538-1539$. 